Original Article

\title{
A HPLC-MS/MS METHOD DEVELOPMENT AND VALIDATION FOR THE SIMULTANEOUS DETERMINATION OF NIFEDIPINE AND ENALAPRIL IN HUMAN PLASMA
}

\section{LILIYA LOGOYDA}

Pharmaceutical Chemistry Department, Pharmaceutical Faculty, I. Horbachevsky Ternopil State Medical University, Ternopil City, Ukraine Email: logojda@tdmu.edu.ua

Received: 30 Dec 2017, Revised and Accepted: 13 Feb 2018

\section{ABSTRACT}

Objective: The main purpose of this study was to develop a simple, precise, rapid and accurate method for the simultaneous quantification of nifedipine and enalapril in human plasma.

Methods: Chromatography was achieved on Discovery C18, $50 \times 2.1 \mathrm{~mm}, 5 \mu \mathrm{m}$ column. Samples were chromatographed in a gradient mode (eluent A (acetonitrile-water-formic acid, 5: 95: $0.1 \mathrm{v} / \mathrm{v}$ ), eluent B (acetonitrile-formic acid, 100: 0.1 v/v)). The initial content of the eluent B is 0\%, which increases linearly by $1.0 \mathrm{~min}$ to $100 \%$ and to $1.01 \mathrm{~min}$ returns to the initial $0 \%$. The mobile phase was delivered at a flow rate of $0.400 \mathrm{ml} / \mathrm{min}$ into the mass spectrometer ESI chamber. The sample volume was $5 \mu \mathrm{l}$.

Results: The total chromatographic run time was $2.5 \mathrm{~min}$ and the elution of nifedipine, enalapril and IS (verapamil) occurred at $\sim 1.83,1.57$ and $1.61 \mathrm{~min}$, respectively. A linear response function was established at $1-100 \mathrm{ng} / \mathrm{ml}$ for nifedipine and $2-200 \mathrm{ng} / \mathrm{ml}$ for enalapril maleate in human plasma. The \% mean recovery for enalapril in LQC, MQC and HQC was $114.0 \%, 112.9 \%$ and $113.2 \%$, for nifedipine in LQC, MQC and HQC was 104.1 $\%, 105.0 \%$ and $108.7 \%$ respectively. The lowest concentration with the RSD $<20 \%$ was taken as LLOQ and was found to be 2.16 ng/ml for enalapril, $1.01 \mathrm{ng} / \mathrm{ml}$ for nifedipine. The \% accuracy of LLOQ samples prepared with the different biological matrix lots was found $108.2 \%$ for enalapril and $100.5 \%$ for nifedipine, which were found within the range of 80.00-120.00\% for the seven different plasma lots. \% CV for LLOQ samples was observed as $3.2 \%$ and $7.4 \%$ respectively, which are within $20.00 \%$ of the acceptance criteria.

Conclusion: A rapid method was developed for simultaneous determination of nifedipine and enalapril in human plasma. The method was strictly validated according to the ICH guidelines. Acquired results demonstrate that proposed strategy can be effortlessly and advantageously applied for routine examination of nifedipine and enalapril in human plasma.

Keywords: HPLC-MS/MS, Nifedipine, Enalapril, Validation, Human plasma

(C) 2018 The Authors. Published by Innovare Academic Sciences Pvt Ltd. This is an open access article under the CC BY license (http://creativecommons.org/licenses/by/4.0/) DOI: http://dx.doi.org/10.22159/ijap.2018v10i4.24528

\section{INTRODUCTION}

Hypertension plays a causative role in the onset of stroke, myocardial infarction, heart failure, peripheral arterial disease, and chronic kidney disease. Currently, antihypertensive drugs include thiazide diuretics, angiotensin-converting enzyme (ACE) inhibitors, calcium channel blockers, $\beta$-blockers, and angiotensin II receptor antagonists.

Nifedipine (fig. 1) has been formulated as both a long and short-acting 1,4-dihydropyridine calcium channel blocker. It acts primarily on vascular smooth muscle cells by stabilizing voltage-gated L-type calcium channels in their inactive conformation. By inhibiting the influx of calcium in smooth muscle cells, nifedipine prevents calcium-dependent myocyte contraction and vasoconstriction. A second proposed mechanism for the drug's vasodilatory effects involves pH-dependent inhibition of calcium influx via inhibition of smooth muscle carbonic anhydrase. Nifedipine is used to treat hypertension and chronic stable angina. Enalapril (fig. 2) is a prodrug that belongs to the angiotensinconverting enzyme (ACE) inhibitor class of medications. It is rapidly metabolized in the liver to enalaprilat following oral administration. Enalaprilat is a potent, competitive inhibitor of ACE, the enzyme responsible for the conversion of angiotensin I (ATI) to angiotensin II (ATII). ATII regulates blood pressure and is a key component of the renin-angiotensin-aldosterone system (RAAS). Enalapril may be used to treat essential or renovascular hypertension and symptomatic congestive heart failure [1].<smiles>COC(=O)C1=C(C)NC(C)=C(C(=O)OC)C1c1ccccc1[N+](=O)[O-]</smiles>

Fig. 1: Chemical structure of nifedipine

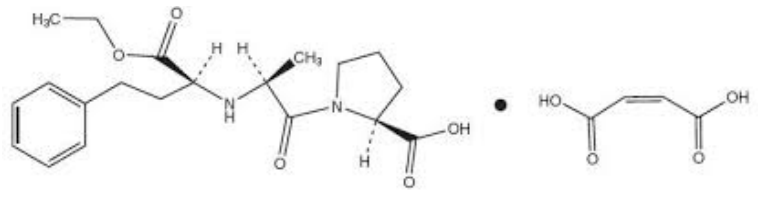

Fig. 2: Chemical structure of enalapril maleate

In the contemporary literature, few bioanalytical methods were reported for quantification of nifedipine and enalapril in human plasma [2-6]. Therefore, it was thought desirable to develop a simple, accurate, cheap and fast procedure that could be applied for the simultaneous determination of nifedipine and enalapril in human plasma, this study performed assay validations as per guidelines [7-9]. While this method with validation details was economical and applied for pharmacokinetic studies of nifedipine and enalapril.

\section{MATERIALS AND METHODS}

\section{Chemicals and reagents}

Nifedipine (purity $100.0 \%$ ), enalapril (purity $99.3 \%$ ), verapamil (Internal Standard) (purity $99.9 \%$ ) were purchased from Moehs Catalana, S. L., Spain, Zhejiang Huahai Pharmaceutical Co., Ltd, KHP, EDQM-Council of Europe. HPLC grade acetonitrile and methanol were purchased from CHROMASOLV, HPLC grade formic acid were purchased from Fluka. All other chemicals and reagents were of analytical grade. Microcaps $\AA$ disposable micropipettes $(50 \mu \mathrm{l}$, catalog number: 1-000-0500) were purchased from Drummond Scientific Company, USA. The control of human dipotassium ethylenediaminetetraacetic acid (K2EDTA) plasma sample was procured from Red Cross Society, Ukraine. 


\section{Instrumentation and chromatographic conditions}

A Shimadzu HT (Shimadzu, Japan) LC system equipped with degasser (DGU-14A), binary pump (LC-20ADXR) along with autosampler (SIL-20AC HT) was used to inject $5 \mu \mathrm{l}$ aliquots of the processed samples on Discovery C18, $50 \times 2.1 \mathrm{~mm}, 5 \mu \mathrm{m}$ column maintained at $25 \pm 1{ }^{\circ} \mathrm{C}$. Samples were chromatographed in a gradient mode (eluent A (acetonitrile-water-formic acid, 5: 95: $0.1 \mathrm{v} / \mathrm{v}$ ), eluent B (acetonitrile-formic acid, 100: $0.1 \mathrm{v} / \mathrm{v}$ )). The initial content of the eluent B is $0 \%$, which increases linearly by $1.0 \mathrm{~min}$ to $100 \%$ and to 1.01 min returns to the initial $0 \%$.

The mobile phase was delivered at a flow rate of $0.400 \mathrm{ml} / \mathrm{min}$ into the mass spectrometer ESI chamber. Parameters of electrospray ionizer and MRM parameters are listed in table 1-2. The analytical data were processed by Analyst Software (version 1.5.2).

Table 1: Parameters of ionizer electrospray

\begin{tabular}{lll}
\hline & Parameter & Value \\
\hline 1 & Polarity & Positive \\
2 & Nebulizer Gas (NEB, Gas 1) & 15 \\
3 & Curtain Gas (CUR) & 8 \\
4 & Collision Gas (CAD) & 4 \\
5 & IonSpray Voltage (IS) & 5000 \\
6 & Temperature (TEM) & 400 \\
7 & Turbo IonSpray Gas & 8 \\
8 & Horizontal Position & 5.3 \\
9 & Lateral Position & 1.3 \\
\hline
\end{tabular}

Table 2: Multiple reaction monitoring (MRM) parameters

\begin{tabular}{|c|c|c|c|c|c|c|c|c|}
\hline ID & Parent, $\mathbf{m} / \mathbf{z}$ & Daughter, $\mathbf{m} / \mathbf{z}$ & Time, ms & DP, V & FP, V & EP, V & CE, V & $\mathrm{CXP}, \mathrm{V}$ \\
\hline Enalapril & 377.165 & 234.2 & 60 & 36 & 130 & 11 & 27 & 18 \\
\hline Nifedipine & 347.128 & 315.1 & 60 & 21 & 100 & 11 & 11 & 24 \\
\hline Verapamil & 455.385 & 165.4 & 60 & 61 & 320 & 11 & 39 & 28 \\
\hline
\end{tabular}

*Abbreviations: DP, declustering potential; FP, focusing potential; EP, entrance potential; CE, collision energy; CXP, collision cell exit potential

\section{Standard solutions}

Nifedipine, enalapril and IS were weighed accurately into volumetric flasks using an analytical microbalance. Approximately $1 \mathrm{mg} / \mathrm{ml}$ primary stock solutions of enalapril, $1 \mathrm{mg} / \mathrm{ml}$ primary stock solutions of nifedipine and $0.5 \mathrm{mg} / \mathrm{ml}$ primary stock solutions of verapamil (IS) solutions were prepared in methanol. The stock solutions were stored at $-20^{\circ} \mathrm{C}$, which was found to be stable for 1 mo. The stock solutions of nifedipine and enalapril were successively diluted with methanol and water to prepare secondary stocks and working solutions. Secondary stock solutions and working solutions were used to prepare calibration curve (CC) and quality control (QC) samples. Working stock solutions were stored at $4{ }^{\circ} \mathrm{C}$ for a week. Working stocks were used to prepare plasma calibration standards. A working IS solution $(20 \mathrm{ng} / \mathrm{ml})$ was prepared in acetonitrile: methanol (50:50 v/v). Blank human plasma was screened before spiking to ensure that it was free from endogenous interference at retention times of nifedipine, enalapril and IS, respectively. Calibration standards' samples $(1-100 \mathrm{ng} / \mathrm{ml}$ for nifedipine, $2-200 \mathrm{ng} / \mathrm{ml}$ for enalapril maleate) were prepared by spiking the blank human K2EDTA plasma with appropriate concentration of nifedipine and enalapril.

Samples for the determination of precision and accuracy were prepared by spiking control human plasma in bulk with nifedipine and enalapril at appropriate concentrations (for nifedipine 3.12 ng/ml low QC [LQC], $31.5 \mathrm{ng} / \mathrm{ml}$ medium QC [MQC], and $81.5 \mathrm{ng} / \mathrm{ml}$ high QC [HQC], for enalapril maleate $6.87 \mathrm{ng} / \mathrm{ml}$ low QC [LQC], 67.7 $\mathrm{ng} / \mathrm{ml}$ medium QC [MQC], and $170.0 \mathrm{ng} / \mathrm{ml}$ high QC [HQC]) and 120 $\mu \mathrm{L}$ plasma aliquots were distributed into different tubes. All the samples were stored at $-80^{\circ} \mathrm{C} \pm 10^{\circ} \mathrm{C}$.

\section{Sample preparation}

A simple protein precipitation extraction method was followed for extraction of nifedipine and enalapril at from human plasma. From the deep freezer, the required quantities of CC standards and QC samples were withdrawn. The samples were thawed at room temperature. To an aliquot of $100 \mu \mathrm{l}$ plasma, $20 \mu \mathrm{l}$ of IS was added. To this mixture, $300 \mu \mathrm{l}$ of acetonitrile: methanol $(50: 50 \mathrm{v} / \mathrm{v})$ was added and vortexed for $2 \mathrm{~min}$, followed by centrifugation at 6000 rpm for $5 \mathrm{~min}$ at $4{ }^{\circ} \mathrm{C}$. After centrifugation, approximately $50 \mu \mathrm{l}$ supernatant was aliquoted into, respectively, labeled autosampler vials, which were later placed in the autosampler at $15^{\circ} \mathrm{C} \pm 4^{\circ} \mathrm{C} .10 \mu \mathrm{l}$ of the sample was injected onto LC-MS/MS system for analysis.

\section{Method validation}

A full validation according to the ICH guidelines was performed for the assay in $\mathrm{K}_{2}$ EDTA human plasma.

\section{Specificity and selectivity}

The specificity of the method was evaluated by analyzing human plasma samples from different lots to investigate the potential interferences at the chromatographic peak region for analytes and IS. The acceptance criterion for the experiment was that should have $<20 \%$ area response to that of the LLOQ level response in the same matrix. Two lots of hemolyzed plasma samples were also analyzed to ensure specificity against potential biological interferences.

\section{Linearity}

The points CC (1-100 ng/ml for nifedipine and $2-200 \mathrm{ng} / \mathrm{ml}$ for enalapril maleate) were constructed by plotting the peak area ratio of each analyte: IS against the nominal concentration of calibration standards in $\mathrm{K}_{2}$ EDTA human plasma. Following the evaluation of different weighing factors, the results were fit into linear regression analysis using 1/X2 (X: Concentration) weighing factor. The CC should have a correlation coefficient ( $r$ ) of 0.99 or better. The acceptance criteria for each back-calculated standard concentration were $\pm 15 \%$ deviation from the nominal value except at LLOQ, which was set at $\pm 20 \%$.

\section{Recovery}

The efficiency of nifedipine, enalapril and IS extraction from human plasma was determined by comparing the responses of the analytes extracted from replicate QC samples $(n=6)$ with those of neat standard solutions spiked in post-extracted plasma blank sample at equivalent concentrations by protein precipitation extraction method. Recovery of enalapril was determined at LQC $(6.87 \mathrm{ng} / \mathrm{ml})$ and HQC $(170.00 \mathrm{ng} / \mathrm{ml})$ concentrations, nifedipine was determined at LQC $(3.12 \mathrm{ng} / \mathrm{ml})$ and HQC $(81.5 \mathrm{ng} / \mathrm{ml})$ concentrations whereas the recovery of IS was determined at a single concentration of 20 $\mathrm{ng} / \mathrm{ml}$. 


\section{Matrix effect}

The effect of human plasma constituents over the ionization of nifedipine, enalapril and IS was determined by post-column infusion method to evaluate matrix effect. Briefly, an infusion pump delivers a constant amount of analyte into LC system outlet entering to mass spectrometer inlet. To follow the analyte signal, the mass spectrometer was operated in MRM mode. The human plasma constituent sample extract was injected on LC column. A steady ion response was obtained as a function of time since the analyte was infused at a constant rate. Any endogenous compound that elutes from the column which causes a variation in ESI response of the infused analyte was seen as a suppression or enhancement in the response of the infused analyte. A separate experiment was performed with nifedipine, enalapril and IS solutions, which were infused at a constant rate, and blank matrix sample injected through the LC. To evaluate matrix effect, different lots of human plasma were spiked with analyte concentration levels at LQC and HQC levels. According to guidelines, the acceptance criterion for each back-calculated concentration was $\pm 15 \%$ deviation from the nominal value.

\section{Precision and accuracy}

The intra-assay precision and accuracy were estimated by analyzing six replicates containing nifedipine, enalaprilat four different QC levels concentrations (for nifedipine $3.12 \mathrm{ng} / \mathrm{ml}$ low $\mathrm{QC}$ [LQC], 31.5 $\mathrm{ng} / \mathrm{ml}$ medium QC [MQC], and $81.5 \mathrm{ng} / \mathrm{ml}$ high QC [HQC], for enalapril maleate $6.87 \mathrm{ng} / \mathrm{ml}$ low QC [LQC], $67.7 \mathrm{ng} / \mathrm{ml}$ medium QC $[\mathrm{MQC}]$, and $170.0 \mathrm{ng} / \mathrm{ml}$ high QC [HQC]) in human plasma. The fourlevel QC samples on four different runs were performed to assess the interassay precision. The acceptance criteria for each backcalculated standard concentration were $85-115 \%$ accuracy from the nominal value except at LLOQ, which was set at $80-120 \%$.

\section{Stability experiments}

Stability tests were conducted to evaluate the stability of nifedipine, enalapril in plasma samples under different conditions. $8 \mathrm{~h}$ bench top stability, processed samples stability (autosampler stability for $26 \mathrm{~h}$ at $10^{\circ} \mathrm{C}$ ), three cycles of freeze-thaw stability, $30 \mathrm{~d}$ of long-term stability at $-80 \pm 10{ }^{\circ} \mathrm{C}$ were performed at $\mathrm{LQC}$ and $\mathrm{HQC}$ levels using six replicates at each level. Samples were considered stable if assay values' acceptance criterion was of accuracy (i.e., $85-115 \%$ from fresh samples) and precision (i.e., $\pm 15 \%$ relative standard deviation [RSD]).

\section{RESULTS AND DISCUSSION}

In the previous study, a rapid, sensitive, and highly selective liquid chromatography-tandem mass spectrometry method was developed and validated for simultaneous determination of enalapril. The analytes were extracted from plasma samples by liquid-liquid extraction, separated on a Zorbax Extend-C(18) column, and detected by tandem mass spectrometry with a Turbo IonSpray ionization interface. The chromatographic run time was $3.5 \mathrm{~min}$ [6].

In the present study, optimization and critical evaluation of mobile phase composition (gradient), flow rate, and analytical column were important to obtain good resolution of peaks of interest from the endogenous components, which in turn affect reproducibility and sensitivity of the method. Selection of chromatographic conditions for the proposed method was optimized to suit the preclinical pharmacokinetic studies. To ease the sample preparation in microtubes and to reduce the usage of solvent, the plasma volume was kept low. Initial feasibility experiments of a various mixture(s) of solvents such as acetonitrile, methanol and formic acid along with altered flow rates (in the range of 0.1-0.6 $\mathrm{ml} / \mathrm{min}$ ) were performed to optimize an effective chromatographic resolution of nifedipine, enalapril and IS. Various analytical columns were tested to obtained good and reproducible response within short run time. The resolution of peaks was best achieved with Discovery C18, $50 \times 2.1$ $\mathrm{mm}, 5 \mu \mathrm{m}$ column. Samples were chromatographed in a gradient mode (eluent A (acetonitrile-water-formic acid, 5: 95: 0.1 v/v), eluent B (acetonitrile-formic acid, 100: $0.1 \mathrm{v} / \mathrm{v}$ )). The initial content of the eluent B is $0 \%$, which increases linearly by $1.0 \mathrm{~min}$ to $100 \%$ and to $1.01 \mathrm{~min}$ returns to the initial $0 \%$. The mobile phase was delivered at a flow rate of $0.400 \mathrm{ml} / \mathrm{min}$ into the mass spectrometer ESI chamber. The injection volume was $5 \mu \mathrm{l}$.

The purpose of sample extraction optimization is mainly to achieve high extraction recovery with negligible or low matrix effects to improve sensitivity and reliability of LC-MS/MS analysis [10-16]. A poor extraction procedure decreases method robustness due to the presence of endogenous interference in the sample extracts, which are not efficiently cleaned up due to poor extraction procedure decreases the method robustness due to the endogenous interference in the sample extracts. With time-saving advantage and simplicity, the protein precipitation extraction method was chosen as an extraction method. The attained LLOQ was sufficient to quantify nifedipine and enalapril in low-dose pharmacokinetic studies.

Nifedipine and enalapril eluted at $\sim 1.83$ and $1.57 \mathrm{~min}$, respectively. During a direct infusion experiment, the mass spectra for nifedipine, enalapril and IS revealed peaks at $\mathrm{m} / \mathrm{z} 347.128,377.165$ and 455.385 , respectively as protonated molecular ions, $[\mathrm{M}+\mathrm{H}]+$. Typical multiple reaction monitoring chromatograms of nifedipine, enalapril and internal standard in dipotassium ethylenediaminetetraacetic acid human blank plasma are shown in fig. 3.

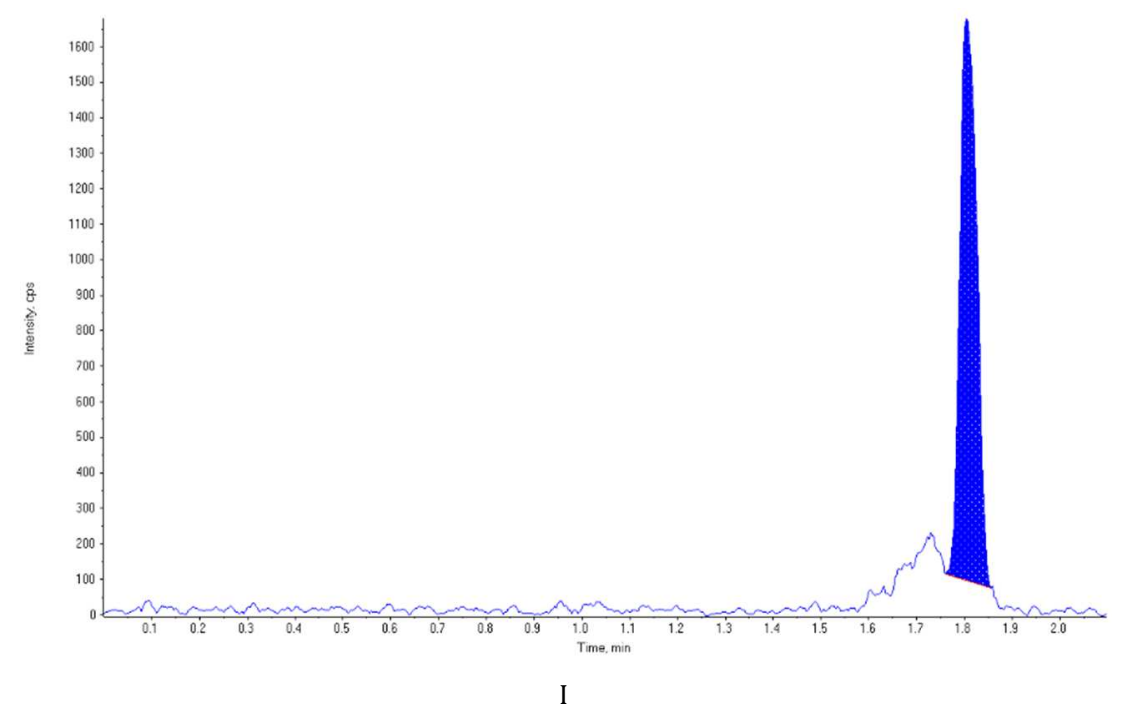




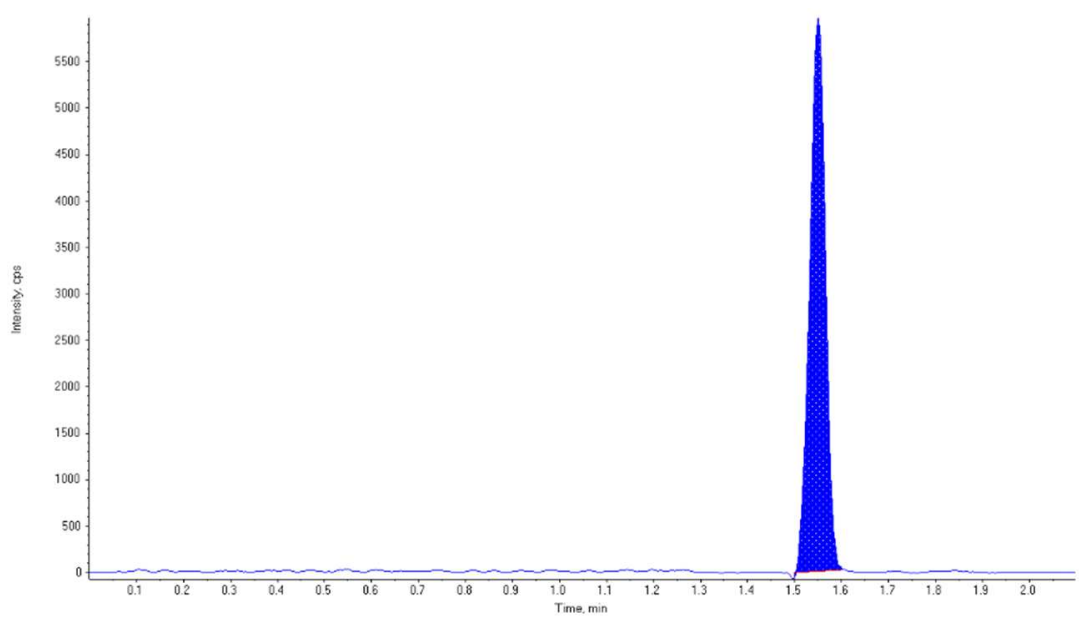

II

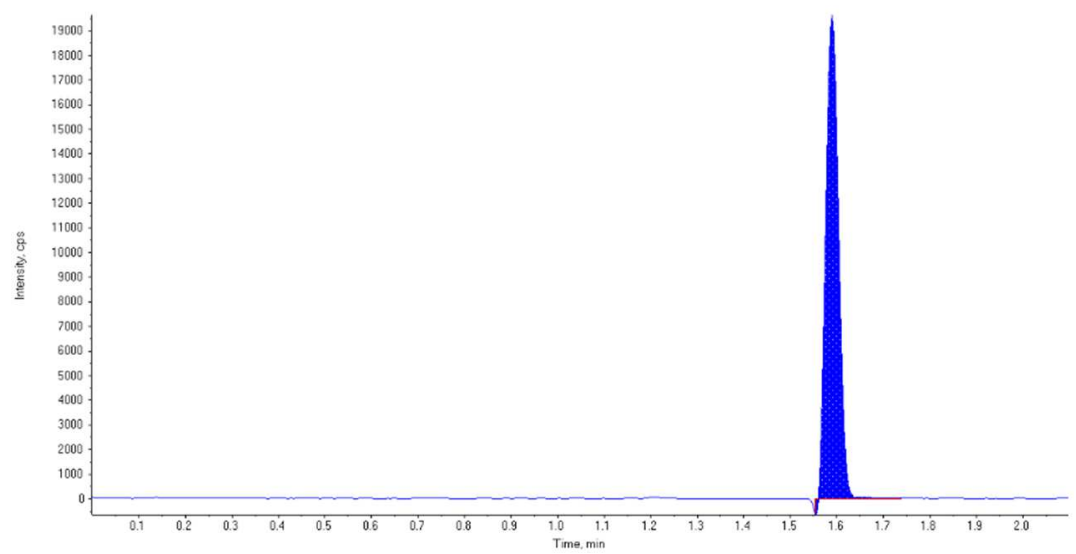

III

Fig. 3: Typical multiple reaction monitoring chromatograms of nifedipine (I), enalapril (II) and internal standard (III) in dipotassium ethylenediaminetetraacetic acid human blank plasma

The total chromatographic run time was $2.5 \mathrm{~min}$ and the elution of nifedipine, enalapril and IS (verapamil) occurred at $\sim 1.83,1.57$ and 1.61 min, respectively.

\section{Specificity}

Different lots of plasma were analysed to ensure that no endogenous interferences were present at the retention time of nifedipine and enalapril LLOQ level samples along with plasma blank from the respective plasma lots were prepared and analysed (table 3).
In all plasma blanks, the response at the retention time of nifedipine and enalapril was less than $20 \%$ of LLOQ response and at the retention time of IS, the response was less than $5 \%$ of mean IS response in LLOQ.

\section{Linearity}

The calibration standard curves had a reliable reproducibility over the standard concentrations across the calibration range. The average regression $(n=3)$ was found to be $>0.997$ for all analytes.

Table 3: Results of specificity for nifedipine and enalapril

\begin{tabular}{|c|c|c|c|c|c|c|c|c|}
\hline \multirow[t]{3}{*}{ S. No. } & \multicolumn{4}{|l|}{ Enalapril } & \multicolumn{4}{|c|}{ Nifedipine } \\
\hline & \multirow[t]{2}{*}{ STD BL } & \multicolumn{2}{|l|}{ LLOQ } & \multirow[t]{2}{*}{$\%$ interference } & \multirow[t]{2}{*}{ STD BL } & \multicolumn{2}{|l|}{ LLOQ } & \multirow[t]{2}{*}{$\%$ Interference } \\
\hline & & Area & RT & & & Area & RT & \\
\hline 1 & 0 & 4332 & 1,55 & NIL & 0 & 1296 & 1,81 & NIL \\
\hline 2 & 0 & 4433 & 1,55 & NIL & 0 & 1154 & 1,81 & NIL \\
\hline 3 & 0 & 4688 & 1,55 & NIL & 0 & 1136 & 1,81 & NIL \\
\hline 4 & 0 & 4328 & 1,55 & NIL & 0 & 1337 & 1,81 & NIL \\
\hline 5 & 0 & 4752 & 1,56 & NIL & 0 & 1353 & 1,81 & NIL \\
\hline 6 & 0 & 4759 & 1,55 & NIL & 0 & 1337 & 1,81 & NIL \\
\hline 7 & 0 & 4750 & 1,55 & NIL & 0 & 1353 & 1,80 & NIL \\
\hline 8 & 0 & 4688 & 1,55 & NIL & 0 & 1337 & 1,81 & NIL \\
\hline 9 & 0 & 4332 & 1,55 & NIL & 0 & 1296 & 1,81 & NIL \\
\hline 10 & 0 & 4433 & 1,55 & NIL & 0 & 1353 & 1,81 & NIL \\
\hline
\end{tabular}

*Average of triplicate injections 


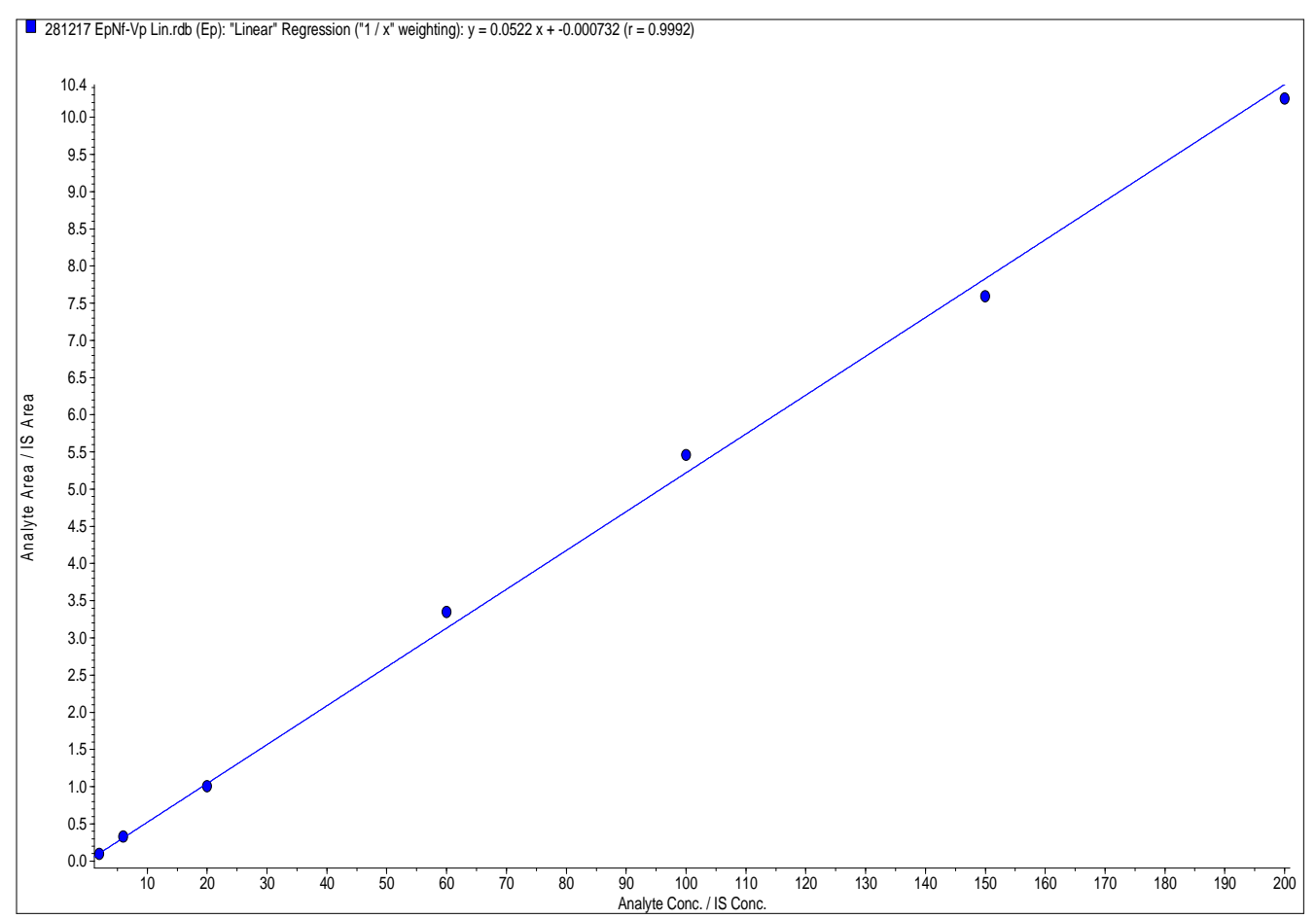

Fig. 4: The calibration curve of enalapril maleate in human plasma

The calibration curve (fig. 4) (peak area ratio Vs Concentration) was linear over working range for enalapril maleate of 2 to $200.00 \mathrm{ng} / \mathrm{ml}$ with 7 point calibration used for quantification by linear regression, shown in fig. 4. The regression equation for the analysis was

$\mathrm{Y}=0.0522 \mathrm{x}-0.000732$ with coefficient of correction $(\mathrm{r} 2)=0.9992$.

The calibration curve (fig. 5) (peak area ratio Vs Concentration) was linear over working range for nifedipine of 1 to $100.00 \mathrm{ng} / \mathrm{ml}$ with 7 point calibration used for quantification by linear regression, shown in fig. 5. The regression equation for the analysis was

$\mathrm{Y}=0.0323 \mathrm{x}-0.00121$ with coefficient of correction $(\mathrm{r} 2)=0.9987$.

\section{Recovery}

The \% mean recovery for enalapril and nifedipine in LQC, MQC and HQC are listed in tables 4-5.

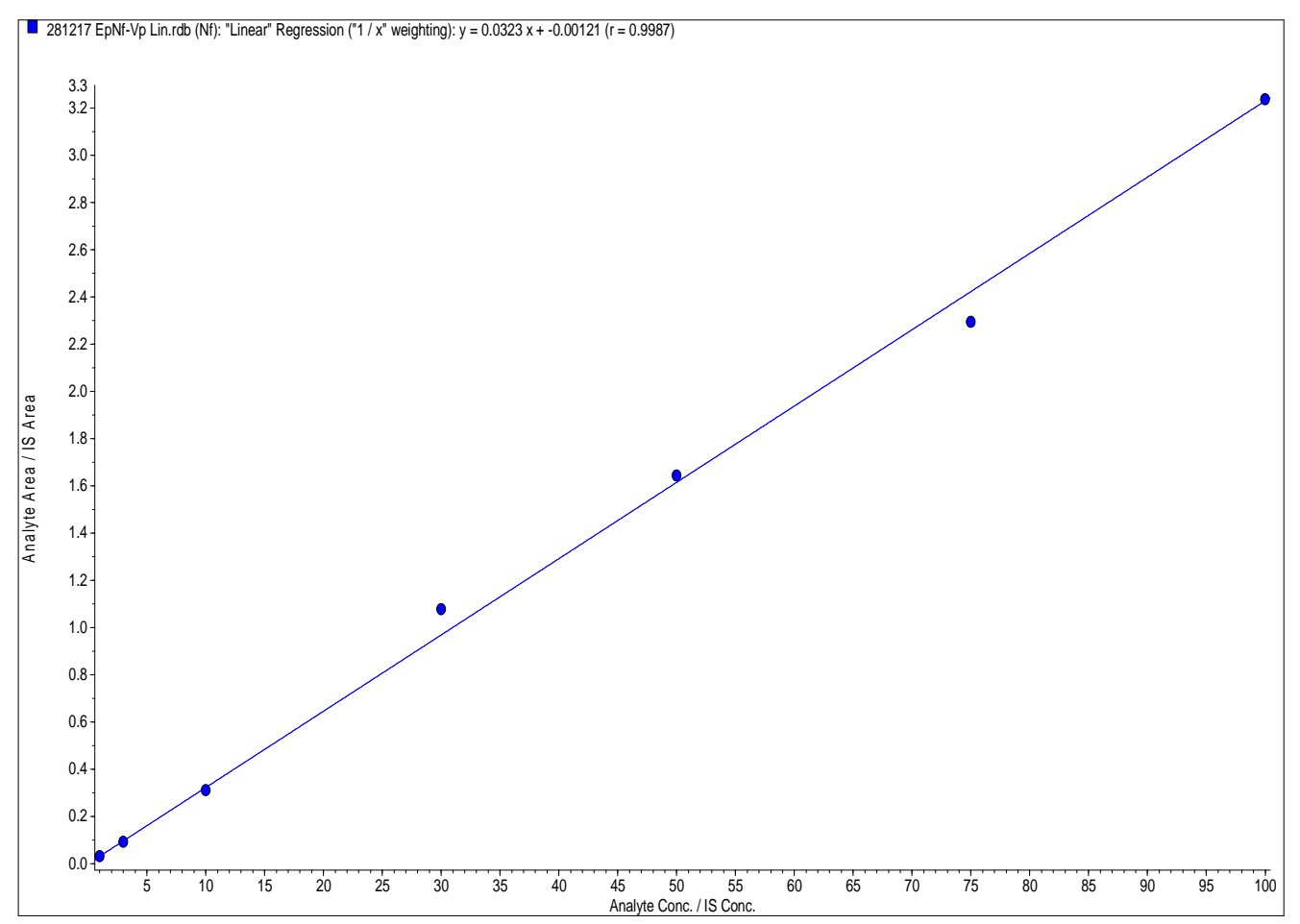

Fig. 5: The calibration curve of nifedipine in human plasma 
Table 4: The \% mean recovery of enalapril for LQC, MQC and HQC

\begin{tabular}{|c|c|c|c|}
\hline S. No. & LQC & MQC & HQC \\
\hline 1 & 6.82 & 66.6 & 164 \\
\hline 2 & 7.12 & 65.6 & 161 \\
\hline 3 & 6.78 & 65.8 & 176 \\
\hline 4 & 6.97 & 71.3 & 171 \\
\hline 5 & 6.52 & 69.3 & 177 \\
\hline Mean & 6.84 & 67.7 & 170 \\
\hline SD & 0.226 & 2.47 & 7.29 \\
\hline$\% \mathrm{CV}$ & 3.3 & 3.6 & 4.3 \\
\hline$\%$ Mean Recovery & 114.0 & 112.9 & 113.2 \\
\hline
\end{tabular}

* Abbreviations: Lower quality control (LQC), middle-quality control (MQC), higher quality control (HQC), Each value is represented as a mean \pm SD of 5 observations $(n=5)$, SD: Standard Deviation, RSD: Relative Standard Deviation, \#Acceptance criteria $<2.0$.

Table 5: The \% mean recovery of nifedipine for LQC, MQC and HQC

\begin{tabular}{|c|c|c|c|}
\hline S. No. & LQC & MQC & HQC \\
\hline 1 & 3.13 & 31.3 & 80.2 \\
\hline 2 & 3.29 & 29.8 & 72.5 \\
\hline 3 & 3.04 & 31.2 & 80.2 \\
\hline 4 & 3.22 & 30.5 & 88.0 \\
\hline 5 & 2.94 & 34.9 & 86.9 \\
\hline Mean & 3.12 & 31.5 & 81.5 \\
\hline SD & 0.140 & 1.97 & 6.27 \\
\hline$\% \mathrm{CV}$ & 4.5 & 6.3 & 7.7 \\
\hline \% Mean Recovery & 104.1 & 105.0 & 108.7 \\
\hline
\end{tabular}

*Abbreviations: Lower quality control (LQC), middle-quality control (MQC), higher quality control (HQC), Each value is represented as a mean \pm SD of 5 observations ( $\mathrm{n}=5$ ), SD: Standard Deviation, RSD: Relative Standard Deviation, \#Acceptance criteria $<2.0$.

The \% mean recovery for enalapril in LQC, MQC and HQC was 114.0 $\%, 112.9 \%$ and $113.2 \%$, for nifedipine in LQC, MQC and HQC was $104.1 \%, 105.0 \%$ and $108.7 \%$ respectively.

Intraday (within run) and Inter-day (between run) precision and accuracy

The within-run coefficients of variation ranged between $0.331 \%$ and $0.619 \%$ for nifedipine. The within-run percentages of nominal concentrations ranged between $98.80 \%$ and $100.63 \%$ for nifedipine. The between-run coefficients of variation ranged between $0.332 \%$ and $0.615 \%$ for nifedipine. The between-run percentages of nominal concentrations ranged between $98.98 \%$ and $101.71 \%$ for nifedipine. Results are presented in table 6 . The assay values on both the occasions (intra-and inter-day) were found to be within the accepted limits.

The within-run coefficients of variation ranged between $0.353 \%$ and $0.719 \%$ for enalapril. The within-run percentages of nominal concentrations ranged between $99.23 \%$ and $101.17 \%$ for enalapril. The between-run coefficients of variation ranged between $0.349 \%$ and $0.674 \%$ for enalapril. The between-run percentages of nominal concentrations ranged between $99.57 \%$ and $101.79 \%$ for enalapril. Results are presented in table 7.

Table 6: Intra-day and Inter-day precision data of nifedipine

\begin{tabular}{lllll}
\hline Day & Intra-day precision & & Inter-day precision \\
\cline { 2 - 5 } & Mean & RSD \% & Mean & RSD \% \\
\hline 1 & 98.80 & 0.378 & 101.71 & 0.332 \\
2 & 100.41 & 0.619 & 98.98 & 0.390 \\
3 & 100.63 & 0.331 & 100.53 & 0.615 \\
\hline
\end{tabular}

*Each value is represented as a mean \pm SD of observations, SD: Standard Deviation, RSD: Relative Standard Deviation, \#Acceptance criteria $<2.0$

Table 7: Intra-day and Inter-day precision data of enalapril

\begin{tabular}{lllll}
\hline Day & Intra-day precision & & Inter-day precision \\
\cline { 2 - 5 } & Mean & RSD \% & Mean & 101.79 \\
\hline 1 & 99.23 & 0.353 & 99.57 & 0.514 \\
2 & 101.17 & 0.719 & 100.13 & 0.349 \\
3 & 100.82 & 0.376 & 0.674 \\
\hline
\end{tabular}

*Each value is represented as a mean \pm SD of observations, SD: Standard Deviation, RSD: Relative Standard Deviation, \#Acceptance criteria<2.0

\section{Matrix effect}

The lowest concentration with the RSD $<20 \%$ was taken as LLOQ and was found to be $2.16 \mathrm{ng} / \mathrm{ml}$ for enalapril, $1.01 \mathrm{ng} / \mathrm{ml}$ for nifedipine. The \% accuracy of LLOQ samples prepared with the different biological matrix lots was found $108.2 \%$ for enalapril and $100.5 \%$ for nifedipine, which were found within the range of 80.00-120.00\% for the seven different plasma lots. \% CV for LLOQ samples was observed as $3.2 \%$ and $7.4 \%$ respectively, which are within $20.00 \%$ of the acceptance criteria. Results are presented in tables 8-9. 
Table 8: Results of matrix effect of enalapril

\begin{tabular}{ll}
\hline S. No. & LLQC \\
\hline 1 & 2.08 \\
2 & 2.19 \\
3 & 2.23 \\
4 & 2.10 \\
5 & 2.22 \\
Mean & 2.16 \\
SD & 0.070 \\
\% Mean Recovery & 3.2 \\
\hline
\end{tabular}

* Abbreviations: Lower limit of quantification (LLOQ), Each value is represented as a mean \pm SD of 5 observations ( $\mathrm{n}=5$ ), SD: Standard Deviation, RSD: Relative Standard Deviation, \#Acceptance criteria $<2.0$.

Table 9: Results of matrix effect of nifedipine

\begin{tabular}{ll}
\hline S. No. & LLQC \\
\hline 1 & 1.04 \\
2 & 0.950 \\
3 & 0.906 \\
4 & 1.08 \\
5 & 1.05 \\
Mean & 1.01 \\
SD & 0.074 \\
\% CV & 7.4 \\
\hline
\end{tabular}

*Abbreviations: Lower limit of quantification (LLOQ), Each value is represented as a mean \pm SD of 5 observations (n=5), SD: Standard Deviation, RSD: Relative Standard Deviation, \#Acceptance criteria $<2.0$.

\section{Stability}

The predicted concentrations for nifedipine $(3.12 \mathrm{ng} / \mathrm{ml}$ and 81.5 $\mathrm{ng} / \mathrm{ml})$ and enalapril $(6.87 \mathrm{ng} / \mathrm{ml}$ and $170.0 \mathrm{ng} / \mathrm{ml})$ deviated within $\pm 15 \%$ of the fresh sample concentrations in a battery of stability tests namely, in-injector $(22 \mathrm{~h})$, bench-top $(7 \mathrm{~h})$, and repeated four freeze/thaw cycles stability (table 13).

Table 13: Stability data of bisoprolol, enalapril, enalapril at QCs in human plasma

\begin{tabular}{|c|c|c|c|c|}
\hline \multirow{2}{*}{ Nominal concentration $(\mathrm{ng} / \mathrm{ml})$} & \multirow{2}{*}{ Stability } & \multicolumn{3}{|l|}{ Stability data } \\
\hline & & $\operatorname{mean} \pm S D{ }^{\circ}(n=6)$ & Accuracy (\%)• & Precision (\% CV) \\
\hline \multirow[t]{4}{*}{ Nifedipine-3.12 } & $0 \mathrm{~h}$ & $3.11 \pm 0.43$ & 99.6 & 2.24 \\
\hline & $7 \mathrm{~h}$ (bench-Top) & $3.11 \pm 0.37$ & 99.6 & 2.34 \\
\hline & $22 \mathrm{~h}$ (in-injector) & $3.10 \pm 0.39$ & 99.3 & 2.46 \\
\hline & 3 FT cycles & $3.09 \pm 0.41$ & 99.0 & 2.36 \\
\hline \multirow[t]{4}{*}{ Enalapril-6.87 } & $0 \mathrm{~h}$ & $6.86 \pm 0.33$ & 99.8 & 3.09 \\
\hline & 7 h (bench-Top) & $6.86 \pm 0.25$ & 99.8 & 2.55 \\
\hline & $22 \mathrm{~h}$ (in-injector) & $6.86 \pm 0.49$ & 99.8 & 3.17 \\
\hline & 3 FT cycles & $6.86 \pm 0.39$ & 99.8 & 2.17 \\
\hline \multirow[t]{4}{*}{ Nifedipine-81.5 } & $0 \mathrm{~h}$ & $81.4 \pm 0.49$ & 99.8 & 2.09 \\
\hline & 7 h (bench-Top) & $81.4 \pm 0.51$ & 99.8 & 3.31 \\
\hline & $22 \mathrm{~h}$ (in-injector) & $81.4 \pm 0.42$ & 99.8 & 2.31 \\
\hline & 3 FT cycles & $81.3 \pm 0.51$ & 99.7 & 3.06 \\
\hline \multirow[t]{4}{*}{ Enalapril-170.0 } & $0 \mathrm{~h}$ & $170.0 \pm 0.51$ & 100.0 & 3.12 \\
\hline & 7 h (bench-Top) & $169.7 \pm 0.31$ & 99.8 & 2.32 \\
\hline & $22 \mathrm{~h}$ (in-injector) & $169.6 \pm 0.24$ & 99.7 & 2.07 \\
\hline & 3 FT cycles & $169.2 \pm 0.61$ & 99.5 & 3.27 \\
\hline
\end{tabular}

${ }^{\circ}$ Back-calculated plasma concentrations; •Mean assayed concentration/mean assayed concentration at $0 \mathrm{~h} \times 100$. FT: Freeze-thaw, SD: Standard deviation, QC: Quality control, the results were found to be within the assay variability limits during the entire process.

\section{CONCLUSION}

A highly sensitive, specific, reproducible, rapid and high-throughput LC-MS/MS assay was developed and validated to quantify nifedipine and enalapril in human plasma as per the regulatory guidelines. The present method involved a simple precipitation method of sample preparation, which gave consistent and reproducible recoveries. Acquired results demonstrate that proposed strategy can be effortlessly and advantageously applied for routine examination of nifedipine and enalapril in human plasma. The combination was taken up for developing a bioanalytical method development and validation so that further it would be useful for performing pharmacokinetic studies.

\section{AUTHOR CONTRIBUTION}

All the work have been carried out by me

\section{CONFLICT OF INTERESTS}

Declared none

\section{REFERENCES}

1. https://www.drugbank.ca [Last accessed on 20 Nov 2017]

2. Kondratova Y, Adebayo T, Logoyda L, Korobko D, Berdey I, Kuchmerovska T. Development of the methodology of the chromatographic determination of amlodipine in medicines. Int J Res Ayurveda Pharm 2016;7:32-5. 
3. Bhardwaj SP, Singh S. Study of forced degradation behavior of enalapril maleate by LC and LC-MS and development of a validated stability-indicating assay method. J Pharm Biomed Anal 2008;46:113-20.

4. Ghosh C, Jain I, Shinde CP, Chakraborty BS. Rapid and sensitive liquid chromatography/tandem mass spectrometry method for simultaneous determination of enalapril and its major metabolite enalaprilat, in human plasma: application to a bioequivalence study. Drug Testing Anal 2012;4:94-103.

5. Danafar H, Hamidi M. Liquid chromatography-tandem mass spectrometry (LC-MS) method for the assignment of enalapril and enalaprilat in human plasma. Pharm Biomed Res 2015;1:47-58.

6. Gu Q, Chen X, Zhong D, Wang Y. Simultaneous determination of enalapril and enalaprilat in human plasma by liquid chromatography-tandem mass spectrometry. J Chromatogr B: Anal Technol Biomed Life Sci 2004;813:337-42.

7. Guideline on Bioanalytical method validation: European Medicines Agencies; 2011.

8. Sonawane LV, Poul BN, Usnale SV. Bioanalytical method validation and its pharmaceutical application a review. Pharm Anal Acta 2014;5:1-7.

9. Pushpa Latha E, Sailaja B. Bioanalytical method development and validation by HPLC: a review. J Appl Pharm 2014;1:1-9.
10. Logoyda L, Abdel-Megied AM, Kondratova Y, Trofimenko O, Korobko D, Dakhym I. Development and validation of HPLC method for the simultaneous determination of enalapril maleate in present of their impurities: application to tablet analysis. Int J Appl Pharm 2018;10:98-102.

11. Delma D'cruz, Anu Babu, Eena Joshy, Aneesh TP. Bioanalytical method development and validation of ticagrelor by RP-HPLC. Int J Appl Pharm 2017;9:51-4.

12. Liliya Logoyda, Yuliya Kondratova, Dmytro Korobko, Yuriy Soroka. Development of UHPLC method for the determination of captopril in pharmaceutical dosage forms. Asian J Pharm Clin Res 2017;10:308-10.

13. Liliya L, Dmytro K, Olena S, Ihor B, Tamara K. Development of methodology for identification of captopril in medicines. Asian J Pharm 2016;10:168-71.

14. Olgya Polyauk, Liliya Logoyda. The investigation of conditions of API from group of calcium channel blockers extraction by organic solvents by using high-performance liquid chromatography as method assay. Asian J Pharm Clin Res 2017;10:354-6

15. Asha B Thomas, Ashish Naphade, Snehal S Karanjkhele. Determination of alprazolam and fluoxetine $\mathrm{HCl}$ from spiked rat plasma using HPTCL with UV deterction. Int J Pharm Pharm Sci 2016;8:147-51. 